comet appeared in the west ; it was like a great Pei Kow (a kind of measure). The luminous envelope was scattered; it appeared like a broken-up star. It was sixty cubits in length and three cubits in breadth. Its direction was to the north-east; it passed through $\mathrm{K}$ wei, Lew, Wei, Maou, and Peih, which are sidereal divisions determined according to Biot by the stars $\beta$ Andromedæ, $\beta$ Arietis, $a$ Musca, $\eta$ Tauri, and $\epsilon$ Tauri respectively. "It then entered into the clouds, and was no more seen." Gaubil's manuscript, used by Pingré, assigns precisely the same course.

European historians relate that on February 4 (or according to others on the following day) a star was seen which was distant from the sun only "a foot and a half;" Matthew Paris and Matthew of Westminster call this star a comet. On February 7 a comet, properly so called, was discovered in Palestine in "that part of the sky where the sun sets in winter," its ray had "the whiteness of snow," and extended to the commencement of the sign Gemini, below the constellation Orion. As Pingré points out the comet must at this time have had a south latitude, and, considering the sun's position, could not be less advanced than $10^{\circ}$ or $12^{\circ}$ of Pisces to have been seen in the evening after sunset. The comet subsequently passed by west to north-west, the tail directed to that part of the sky between the north and the east ; the comet was visible until the middle of the night, and "shone during twenty-five days in the same manner at the same hour ;" as one writer states, it had a real motion from west to east. The length of the comet's appearance is variously given; an eye-witness says that the most piercing sight could hardly distinguish it after fifty days, and a manuscript consulted by Pingré, in the Bibliothèque de SainteGeneviève, of the thirteenth century at latest, mentions fifty-six days for the duration of visibility.

The comet of 1106 long attracted attention from the circumstance of Halley having identified it as the famous comet of 1680 , an idea which was first disputed by Dunthorne, on the authority of a manuscript preserved in one of the College libraries at Cambridge, which gives the comet's track from the beginning of the sign Pisces (on February 7 as Dunthorne reads) in the order of the signs to the commencement of Cancer, which agrees closely with the path recorded by the Chinese. He considered that this track "quite overbalanced the probability of the identity of the comet with that of 1680 "-and this view has been confirmed by subsequent calculation. Again, when astronomers were searching for earlier accounts which might refer to the great comet of 1843 , first detected at noon-day on the date of its perihelion passage, this comet of IIO6 was fixed upon by MM. Laugier and Mauvais, as probably identical with it, several of the circumstances mentioned above being overlooked by them, particularly the fact of the comet having been observed so long in the northern part of the heavens, where it is impossible that the comet of 1843 could be located.

On carefully weighing the scanty evidence afforded by the records of the time, it appears likely that the elements of the comet of I I06 bore some resemblance to those of the great comet of 1618 (Pingrés third comet), the inclination being smaller.

The Satellites of MARS.--Both of the newly-dis covered satellites of Mars were observed during September with the 12 -inch equatorial of the Morrison Observatory, Glasgow, Missouri, by Mr. Pritchett. On September 7 the two satellites could be seen with the planet entirely in the field, and were very distinct when it was shut out of it, and on September Io and 13, the inner one was easily observed. The outer satellite was again estimated to be of the fourteenth magnitude. The observations of this satellite were made with wires faintly illuminated with a red light; for observations of the inner one the light of the planet sufficed. Unfavour- able skies prevented any observations in October, though $\mathrm{Mr}$. Pritchett thinks the satellites might have been well followed during that month.

COLOURED DOUBLE STARs.-In Sir John Herschel's seventh catalogue of double stars from the sweeps with the 20 -feet reflector is one the position of which identifies it with $\Sigma 724$, and the note attached runs thus: "A very curious double star, the small star is very red." The ckservation belongs to sweep No. I2I, for the epoch

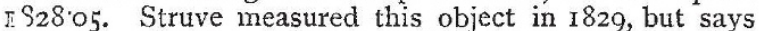
nothing respecting the colours of the components, which he estimated on his scale 8.7 and $10^{\circ} 0$. In $1829^{\circ} 85$ the angle was $241^{\circ} 5^{\circ}$, and the distance $6.86^{\prime \prime}$. Has any one confirmed Sir John Herschel's observation on the colour of the smaller star? The position for $187^{\circ} \circ$ is in R.A. 5h. 33 m. $305 .$, N.P.D. $79^{\circ} 5^{\prime \prime} 5$.

In Memorie del Osservatorio del Collegio Romano, I857-59, p, 173, Secchi mentions a wide double star, which is called nova, and is thus measured :-

1856.63 Pos. $335^{\circ} \cdot 25$ Dist. $23^{\prime \prime} \cdot 83\left\{\begin{array}{l}\text { Components } 7 \mathrm{~m} \text {. and } 8 \mathrm{~m} \text {. } \\ \text { A red, B blue. }\end{array}\right.$

He has the additional remark, "Colori superbi." This object would appear to be formed by Nos. 3743 and 3744 of Zone $+37^{\circ}$ of the Durchmusterung; positions for $1855^{\circ} 0:-$

$\begin{array}{ccccc}3743 & \text { R.A. } & \text { 19 } 5823.5 & \text { N.P.D. } & 524.1 \\ 3744 & \text { \% } & 195825.5 & \Rightarrow & 5247\end{array}$

\section{THE TALKING PHONOGRAPH 1}

M R. THOMAS A. EDISON recently came into this I 1 office, placed a little machine on our desk, turned a crank, and the machine inquired as to our health, asked how we liked the phonograph, informed us that it was well, and bid us a cordial good night. These remarks were not only perfectly audible to ourselves, but to a dozen or more persons gathered around, and they were produced by the aid of no other mechanism than the simple little contrivance explained and illustrated below.

The principle on which the machine operates we

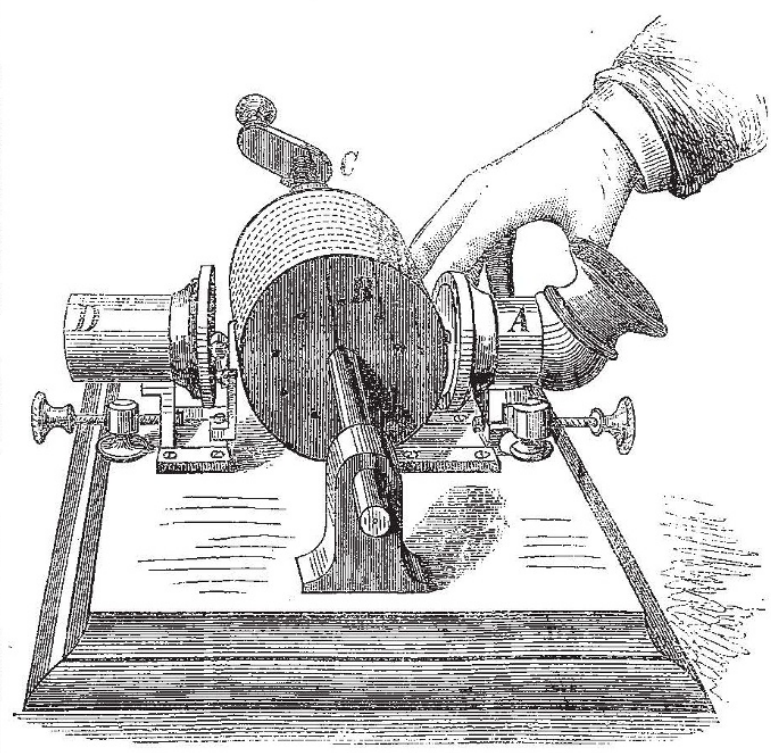

FIG. I.

recently explained quite fully in announcing the discovery. There is, first, a mouth-piece, A, Fig. I, across the inner orifice of which is a metal diaphragm, and to the centre of this diaphragm is attached a point, also of metal. B is a 
brass cylinder supported on a shaft which is screwthreaded, and turns in a nut for a bearing, so that when the cylinder is caused to revolve by the crank, c, it also has a horizontal travel in front of the mouthpiece, A. It will be clear that the point on the metal diaphragm must, therefore, describe a spiral trace over the surface of the cylinder. On the latter is cut a spiral groove of like pitch to that on the shaft, and around the cylinder is attached a strip of tinfoil. When sounds are uttered in the mouth-piece, A, the diaphragm is caused to vibrate, and the point thereon is caused to make contacts with the tinfoil at the portion where the latter crosses the spiral groove. Hence, the foil, not being there backed by the solid metal of the cylinder, becomes indented, and these indentations are necessarily an exact record of the sounds which produced them.

It might be said that at this point the machine has already become a complete phonograph or sound writer, but it yet remains to translate the remarks made. It should be remembered that the Marey and Rosapelly, the Scott or the Barlow apparatus, which we recently described, proceed no further than this. Each has its own system of caligraphy, and after it has inscribed its peculiar sinuous lines, it is still necessary to decipher them. Perhaps the best device of this kind ever contrived was the preparation of the human ear made by Dr. Clarence $J$. Blake, of Boston, for Prof. Bell, the inventor of the telephone. This was simply the ear from an actual subject, suitably mounted, and having attached to its drum a straw, which made traces on a blackened rotating cylinder. The difference in the traces of the sounds uttered in the

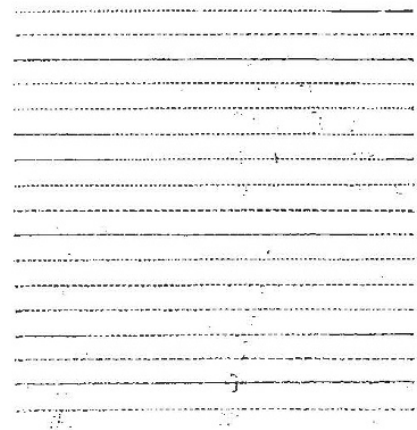

F'ıG. 2.

ear was very clearly shown. Now there is no doubt that by practice and the aid of a magnifier, it would be possible to read phonetically Mr. Edison's record of dots and dashes, but he saves us that trouble by literally making it read itself. The distinction; is the same as if, instead of perusing a book ourselves we drop it into a machine, set the latter in motion, and, behold ! the voice of the author is heard repeating his own composition.

The reading mechanism is nothing but another diaphragm held in the tube $\mathbf{D}$ on the opposite side of the machine, and a point of metal which is held against the tin foil on the cylinder by a delicate spring. It makes no difference as to the vibrations produced, whether a nail moves over a file or a file moves over a nail, and in the present instance it is the file or indented foil strip which moves, and the metal point is caused to vibrate as it is affected by the passage of the indentations. The vibrations, however, of this point must be precisely the same as those of the other point which made the indentations, and these vibrations, transmitted to a second membrane, must cause the latter'to vibrate similar to the first membrane, and the result is a synthesis of the sounds which, in the beginning, we saw, as it were, analysed.

In order to exhibit to the reader the writing of the machine which is thus automatically read, we have had a cast of a portion of the indented foil made, and from this the dots and lines in Fig. 2 are printed in, of course, absolute facsimile, excepting that they are level instead of being raised above or sunk beneath the surface. This is a part of the sentences, "How do you do?" and "How do you like the phonograph?". It is a little curious that the machine pronounces its own name with especial clearness. The crank handle shown in our perspective illustration of the device does not rightly belong to it, and was attached by Mr. Edison in order to facilitate its exhibition to us.

In order that the machine may be able exactly to reproduce given sounds, it is necessary, first, that these sounds should be analysed into vibrations, and these registered accurately in the manner described; and second, that their reproduction should be accomplished in the same period of time in which they were made, for evidently this element of time is an important factor in the quality and nature of the tones. A sound which is composed of a certain number of vibrations per second is an octave above a sound which registers only half that number of vibrations in the same period. Consequently if the cylinder be rotated at a given speed while registering certiin tones, it is necessary that it should be turned at precisely that same speed while reproducing them, else the tones will be expressed in entirely different notes of the scale, higher or lower than the normal note as the cylinder is turned faster or slower. To attain this result there must be a way of driving the cylinder, while delivering the sound or speaking, at exactly the same rate as it ran while the sounds were being recorded, and this is perhaps best done by well-regulated clockwork. It should be understood that the machine illustrated is but an experimental form, and combines in itself two separate devices-the phonograph or recording apparatus, which produces the indented slip, and the receiving or talking contrivance which reads it. Thus in use the first machine would produce a slip, and this would for example be sent by mail elsewhere, together in all cases with information of the velocity of rotation of the cylinder. The recipient would then set the cylinder of his reading apparatus to rotate at precisely the same speed, and in this way he would hear the tones as they were uttered. Differences in velocity of rotation within moderate limits would by no means render the machine's talking indistinguishable, but it. would have the curious effect of possibly converting the high voice of a child into the deep bass of a man, or vice versî.

No matter how familiar a person may be with modern machinery and its wonderful performances, or how clear in his mind the principle underlying this strange device may be, it is impossible to listen to the mechanical speech without his experiencing the idea that his senses are deceiving him. We have heard other talking machines. The Faber apparatus, for example, is a large affair, as big as a parlour organ. It has a key-board, rubber larynx and lips, and an immense amount of ingenious mechanism which combines to produce something like articulation in a single monotonous organ-note. But here is a little affair of a few pieces of metal, set up roughly on an iron stand about a foot square, that talks in such a way, that, even if in its present imperfect form many words are not clearly distinguishable, there can be no doubt but that the inflections are those of nothing else than the human voice.

We have already pointed out the startling possibility of the voices of the dead being reheard through this device, and there is no doubt but that its capabilities are fully equal to other results just as astonishing. When it becomes possible, as it doubtless will, to magnify the sound, the voices of such singers as Parepa and Titiens will not die with them, but will remain as long as the metal in which they may be embodied will last. The witness in court will find his own testimony repeated by machine, confronting him on cross-examination-the testator will repeat his last will and testament into the machine se 
that it will be reproduced in a way that will leave no question as to his devising capacity or sanity. It is already possible by ingenious optical contrivances to throw stereoscopic photographs of people on screens in full view of an audience. Add the talking phonograph to counterfeit their voices, and it would be difficult to carry the illusion of real presence much further.

\section{NOTES}

Mr. SORBY is busy perfecting his new method of studying minerals. Some very remarkable properties are still unexplained, and only the other day Mr. Sorby made a very great fresh advance in the subject.

IT is probable that Sheffeld will be chosen for the meeting of the British Association in I879. Nottingham was to have been the place of meeting, but a difficulty has arisen respecting the meeting there, and Sheffield has been unofficially written to. The matter is being warmly taken up by some of the principal townsmen, and there can be no doubt with a successful result.

A PHOTOLITHOLRAYHC plate of the primary triangulation of the United States Geological and Geographical Survey of the Territories, carried on during the summer of 1877 , by Mr. A. D. Wilson, chief topographer, has just been published by the United States Geological Survey, under the charge of Dr. F. V. Hayden. The area covered by these triangles extends from Fort Steele, in Wyoming Ty., westward to Ogden, in Utah Ty., a distance of about 260 miles, and north as far as the Grand Teton, near the Yellowstone National Park, including Freemont's Peak of the Wind River Range of the Rocky Mountains. The area embraces about 28,000 square miles, and within it, twenty-six primary stations were occupied, and their positions accurately computed. Besides these occupied stations, a large number of mountain feaks were located, which in the future will be occupied as points for the extension of the topographical work of the Survey. A base line was carefully measured near Rawlin's Springs, on the line of the Union Pacific Railroad, and from this initial base the work was extended north and west to the valley of Bear River, in Idaho Ty. Here a check base was measured, and the system expanded to the neighbouring mountain peaks to connect with the triangulation as brought forward from the first-mentioned base. Along the line of the Union Pacific Railroad the work was connected at six points with the triangulation system of Clarence King's 4oth parallel survey. In addition to the importance of this sheet as the base work of the season's topographical work, it presents a most striking feature in the number of remarkably long sights which were taken from the summits of some of the most lofty moun. tains in the area explored. Many of these sights were over roo miles in length, while some reach a distance of 135 miles. From Wind River Peak all the prominent points in the Big Horn Mountains were sighted, also the loftier peaks of the Uinta Mountains; the former are located 165 miles to the north-east, while the Uinta Mountains are situated about the same distance to the south-west. As these ranges were not in the scope of the seașon's work, they are not given on the chart.

Thr Annual Report of the Smithsonian Institution for the year 1876 , which has recently been published, is of general interest. The Institution continues to carry on its usual work with vigour and efficiency. Two important volumes of the Smithsonian Contributions to Knowledge, xx. and xxi., have been issued. The former on the Winds of the Globe, by Prof. Coffin, consisting of $78 \mathrm{I}$ quarto pages, is considered to be the most important contribution to knowledge which the Institution has given to the world. It presents a rich mine of information for the use of metecrologists, the physical geographer, and the mariner. Volume xxi, contains the following articles, viz. :-(I) Statements and Expositions of Certain Harmonies of the Solar System, by Prof. Alexander, (2) On the General Integral of Planetary Motion, by Prof. Newcomb. (3) The Haidal Indians by J. G. Swan, (4) Tables of Atmospheric Temperature in America. There has been published an important work on the Antiquities of Tennessee, by Dr. Joseph Jones, and another on the Archrological Collections of the U.S. National Museum; also a supplement to Prof. F. W. Clarke's work on the "Constants of Nature," consisting of tables of specific gravities, boiling and melting points, specific heats, \&c. Large additions have during the year been made to the collections of the National Museum in charge of the Institution. In the Appendix to the Report there is a translation of the eulogy on Gay-Lussac by M. Arago; a biographical sketch of Dom Pedro II. ; a translation of an important paper of Prof. Pilar on the Revolutioas of the Earth's Crust, which will be read with interest by students of physical geography and geology. The subjects discussed in this article are the origin of the earth, central heat, the fluid envelope, organisms, ice, with a concise account of the theory of secular changes of climate resulting from changes in the eccentricity of the earth's orbit, antiquity of man, \&c. Then follows a paper by Dr. D. Kirkwood on the Asteroids between Mars and Jupiter. But the article which will probably attract most attention is one by Mr. W. B. Taylor on Kinetic Theories of Gravitation. In this memoir, occupying about eighty pages, is given an interesting historical account of all the principal theories which have been advanced since the time of Newton to the present day to explain the nature of gravitation. Villemot, I707; Bernouilli, $x 734$; Le Sage, xy50; Euler, 1760 ; Herapath, I8r6; Guyot, r832; Faraday, I844; Seguin, 1848; Boucheporn, I849; Lamè, I852 ; Waterston, I858; Challis, 1859 ; Glennie, I861; Keller, 1863; Tait, I864; Saigey, I866; Croll, I867; Leray, 1869; Boisbaudran, 1869; Guthrie, 1870; Crookes, 1873. These theories are all criticised with considerable acuteness. Mr. Taylor lays down six fundamental characteristics of gravity with which, he asserts, every theory must agree. But unfortunately it is in reference to the truth of some of Mr. Taylor's postulates that the greatest cliversity of opinion exists. No kinetic theory of gravitation can fulkl his six conditions. Mr. Taylor seems to misapprehend some of the theories in important points, particularly those of Le Sage and Croll. The Appendix con. cludes with a number of interesting papers on Ethnology.

WE have already referred to Prof. A. Agassiz's intention of carrying out a series of researches in the Gulf of Mexico. With an assistant he is to be accommodated on board the United States Coast Survey steamer Blake, which has just sailed on a surveying cruise that will occupy this winter in the Gulf of Mexico. By" a study of the animals dredged from the bottom of the Gulf, Prof. Agassiz will be enabled to make important comparisons with the fauna of the Atlantic, and especially as to growth, habits, migrations, and changes of living forms found in the waters near the British Islands and the Scandinavian Peninsula. The expedition is under the command of Lieutenant-Commander Charles D. Sigsbee, United States Navy, who has had several years experience on coast survey duty, and has been notably successful in deep-sea soundings.

NEW YoRK will in all probability have a magnificent new Zoological Garden in Central Park before the end of another year. The Park Commissioners have little doubt that the amount of money, 300,000 dollars, necessary to make a come mencement, will be subscribed without difficulty.

THE death is announced of Mr. Robert Hollond, a gentleman formerly well-known in connection with aeronautics.

The Rev. Horace Waller writes to the Times that Col. Mason has been round Lake Albert Nyanza in a steamer, and 